\title{
Effect of capillary tube on the performance of a simple vapour compression refrigeration system
}

\author{
Shashank shekhar pathak ${ }^{1}$, Prakhar shukla ${ }^{2}$, Sanjeev chauhan ${ }^{3}$ \\ ${ }^{1,2,3}$ Department of Mechanical Engineering, S.R.M.C.E.M, Lucknow, India
}

\begin{abstract}
It is essential to study the effect of capillary tube geometry on the performance of refrigeration systems. The literature review focuses on the effect that geometrical parameters like capillary tube length, bore diameter, coil pitch, number of twist and twisted angle have on the pressure drop, coefficient of performance $(C O P)$ and mass flow rate of the system. These parameters can be further studied using physical models and mathematical modeling concepts. The parameters stated above can be further optimized in order to enhance the performance of the refrigeration system.
\end{abstract}

Keywords: Capillary Tube, refrigeration system, twist angle

\section{Introduction}

Instead of an orifice, a small diameter tube can be used for the expansion of the flowing fluid. This small diameter tube is known as the capillary tube expansion device and it produces the same effect as produced by the orifice. The term 'capillary tube' means 'hair-like'. It is so called because of its very small bore diameter. The inside diameter of the capillary tube used for the purpose of refrigeration ranges from about $0.5 \mathrm{~mm}$ to 2.30 $\mathrm{mm}$. longer the capillary tube and/or smaller the inside diameter of the capillary tube, greater is the pressure drop it can create in the refrigerant flow. In other words, greater will be the pressure difference needed between the high pressure side and the low pressure side to establish a given flow rate of the refrigerant.

\section{Literature Review}

Various literature sources are focused towards finding out the influence of the geometrical configurations of a capillary tube on the performance of the refrigeration system. The accurate size of the capillary tube and its configuration can be predicted with the help of the calculations for the refrigeration effect, coefficient of performance (cop) of the system and mass flow rate of the system. The effects of different geometries of capillary tubes have been studied by many researchers. Since the capillary tube can be straight, helical coiled and also serpentine coiled and all three configurations have their own distinct effect on the system performance, thus the literature review here is focused to give a brief introduction of the effects of the various configurations of the capillary tube on the system performance and thus pave the path for further studies.

Hirendra Kumar Paliwal and Keshav Kant (2006) developed a flow model for designing and studying the performance of helical coiled capillary tubes and to mathematically simulate a situation closer to one existing in real practice. Homogeneous flow of two phase fluid was assumed through the adiabatic capillary tube. The model included the second law restrictions. The effect of the variation of different parameters like condenser and evaporator pressures, refrigerant flow rate, degree of sub cooling, tube diameter, internal roughness of the tube, pitch and the diameter of the helix and the length of the capillary tube were included in the model. Theoretically predicted lengths of helical coiled capillary tube for R-134a are compared with the length of the capillary tube actually required under similar experimental conditions and majority of predictions were found to be within around $10 \%$ of the experimental value.

M.Y.Taib et al. (2010) studied the performance of a domestic refrigerator and developed a test rig from refrigerator model NRB33TA. The main objective of the performance analysis was to obtain the performance of the system in terms of refrigeration capacity, coefficient of performance (cop), and compressor work by determining three important parameters which are temperature, pressure and refrigerant flow rate. The analysis of the collected data gave the cop of the system as 2.75 while the refrigeration capacity was ranging from 150 watt to 205 watt.

Sanggoon Park et al. (2008) simulated the effects of a non adiabatic capillary tube on refrigeration cycle. The simulation focused on the effect of capillary tube- suction line heat exchangers (CT-SLHX). The simulation of steady state were based on the fundamental conservation equations of mass and energy and these equations were solved simultaneously through iterative process. The non - adiabatic capillary tube model was based on homogenous two phase model. The length and location of soldering region between capillary tube and suction line tube were changed and performance of the refrigeration cycle was compared in terms of condenser pressure, evaporator pressure, refrigeration effect, compressor work and cop. The simulation results showed that both the location and length of the heat exchange section influence the cop of the system. 
J.K.Dabas et al. (2011) studied the behavior of performance parameters of a simple vapour compression refrigeration system while its working under transient conditions occurred during cooling of a fixed mass of brine from initial room temperature to sub-zero refrigeration temperature. The effects of different lengths of capillary tube over these characteristics were also investigated. The investigation showed that with constantly falling temperature over evaporator, refilling of it with more and more liquid refrigerant causes increase in heat transfer coefficient which maintains the refrigeration rate at falling temperature. The study revealed that larger capillary tubes decreases the tendency of refilling but offers less evaporator temperature while shorter capillary tubes ensure higher cop initially but it deteriorates at a faster rate in lower temperature range.

M.M.Tayde et al. (2013) compared the performance of a miniature vapour compression refrigeration system with four different refrigerants namely NH3, R12, R22 and R134a. The study revealed that NH3 gives maximum value of cop for the system. Next highest cop for the system came out for R12 and then for R134a. Refrigerant R22 gave the least cop for the miniature system.

Nishant P. Tekade et al. (2012) reviewed the investigation about the coiling effect of spiral capillary tubes on the refrigerant mass flow rate for the same cooling load. The work also reviewed the effects of changes in the parameters such as capillary tube dimension i.e. capillary tube diameter, capillary tube length, coil pitch and inlet conditions of the refrigerant to the capillary tube i.e. degree of subcooling and inlet pressure of the refrigerant charge.

Ankush Sharma and Jagdev Singh (2013) experimentally investigated about the effects simple and twisted spirally coiled adiabatic capillary tubes on the refrigerant flow rate. Several capillary tubes with different bore diameters, lengths and pitches were taken as test sections. LPG was used as an alternative for R134a. mass flow rates for different capillary tubes were measured for different degrees of subcooling with constant inlet pressure of the capillary tube. Experiments were conducted on straight capillary tubes as well so as to facilitate proper comparison. The test results showed that mass flow rate is greater in straight capillary tube and least in twisted spirally coiled capillary tube.

Sudharash Bhargava and Jagdev Singh (2013) experimentally investigated the of pitch and length of the serpentine coiled adiabatic capillary tube on the flow of a eco friendly gas. The azeotropic blend ( $30 \%$ propane, 55\% n-butane, 15\% iso-butane) is used as refrigerant in the experiment. Various capillary tubes with distinct lengths, pith and bore diameter were used as the test sections in the experiment. Inlet pressure of the capillary tubes was kept constant and then mass flow rates for different capillary tubes with different lengths and pitches were measured. Straight capillary tubes were also investigated. The data from the experiments showed that mass flow rate of the refrigerant in the system was less for serpentine coiled capillary tubes and was grater for straight capillary tubes.

Thamir K. Salim (2012) experimentally investigated the performance of the capillary tube expansion device using R134a as the refrigerant in the system. All the properties of the refrigeration system was measured for the mass flow rate ranging from $13 \mathrm{~kg} / \mathrm{hour}$ to $23 \mathrm{~kg} /$ hour and capillary tube coil number ( $0-4)$ with fixed length $(150 \mathrm{~cm})$ and capillary tube bore diameter $(2.5 \mathrm{~mm})$. the test results showed that the theoretical compression power increases by $65.8 \%$ as the condenser temperature increases by $2.71 \%$ and the theoretical compression power decreases by $10.3 \%$ as the capillary tube coil number increases. The test results also showed that cooling capacity increases by $65.3 \%$ as evaporator temperature increases by $8.4 \%$ and the cooling capacity increases by $1.6 \%$ as the capillary tube coil number increases in the range (0-4). The cop decreases by $43.4 \%$ as the mass flow rate increases by $76.9 \%$ and the cop of the system increases by $13.51 \%$ as the capillary tube coil number increases in the range (0-4). The study showed that coil number 4 was the best for the lowest mass flow rate $(13 \mathrm{~kg} / \mathrm{hour})$ and the highest mass flow rate ( $23 \mathrm{~kg} / \mathrm{hour})$.

Akash Deep Singh (2009) developed a mathematical model for adiabatic capillary tube. The mathematical model was developed using equations of conservation of mass, momentum and energy and was used for predicting the length of adiabatic capillary tube. Moody (1944) correlation was used to calculate the friction factor. McAdams et al. (1942) viscosity correlation was used to evaluate the two phase viscosity of the refrigerant. Input parameters were taken from the data of Mendoca et al. (1998).A geometric model was developed in Pro-E and the mesh was created in Ansys ICEM CFD and analysis is carried out in Ansys CFX which has three modules CFX-Pre, Solver and CFX-Post.

M.A. Akintunde (2007) investigated the effects of various geometries of capillary tubes based on the coil diameters and lengths alone. There was no any particular attention paid on the effect of coil pitch. This paper examined the effects that the pitches of both helical coiled and serpentine coiled capillary tubes have on the performance of a vapor compression refrigeration system. Several capillary tubes of equal lengths $(2.03 \mathrm{~m})$ and varying pitches, coile diameters and serpentine heights were used. Both the inlet and outlet pressure and the temperature of the test section (capillary tube) were measured and were used to estimate the COP of the system. In the case of helical coiled capillary tubes, the pitch did not have any significant effect on the system performance, while in the case of serpentine coiled capillary tubes, both pitch and height of the serpentine 
influences the system performance. Performance improved with increase in both the pitch and the height. Correlations were proposed to describe the relationships between straight and coiled capillary tubes and between helical coiled capillary tubes and serpentine coiled capillary tubes. The coefficient of correlation proposed was 0.9841 for the mass flow rates of helical and serpentine with straight tubes and 0.9864 for the corresponding COPs and 0.9996 for the mass flow rates of helical and serpentine coiled tubes.

\section{Conclusions}

Optimization of geometrical parameter like the capillary tube diameter, capillary tube length, coil pitch, twisted angle of capillary tube is possible by using experimental modeling and methods, mathematical modelling and by maintaining proper pressure between condenser and evaporator. The effect of such geometrical parameters on the coefficient of performance (COP) of the system, pressure drop, refrigerant flow rate, degree of sub cooling is reviewed in this paper.

\section{References}

[1]. Hirendra Kumar Paliwall, Keshav Kant2 , " A model for helical capillary tubes for refrigeration systems," International Refrigeration and Air Conditioning Conference Purdue University, 2006

[2]. M.Y.Taib, A.A.Aziz and A.B.S.Alias, "Performance analysis of a domestic refrigerator", National Conference in Mechanical Engineering Research and Postgraduate Students, 2010

[3]. Sanggoon Park, Kidong Son, Jihwan Jeong and Lyunsu Kim, "Simulation of the effects of a non-adiabatic capillary tube on refrigeration cycle", International Refrigeration and Air Conditioning Conference, 2008

[4]. J.K.Dabas, A.K.Dodeja, Sudhir Kumar and K.S.Kasana, "Performance characteristics of "vapour compression refrigeration system" under real transient conditions", International Journal of Advancements in Technology, 2011.

[5]. M.M.Tayde, Pranav Datar and Pankaj Kumar, "Optimum choice of refrigerant for miniature vapour compression refrigeration system”, Indian journal of Applied Research, 2013.

[6]. Nishant P. Tekade and Dr. U.S.Wankhede, "Selection of spiral capillary tube for refrigeration appliances", International Journal of Modern Engineering Research, 2012

[7]. Ankush Sharma and Jagdev Singh, "Experimental investigation of refrigerant flow rate with spirally coiled adiabatic capillary tube in vapour compression refrigeration cycle using eco friendly refrigerant", International Journal of Mechanical and Production Engineering Research and Development, 2013.

[8]. Sudharash Bhargava and Jagdev Singh, "Experimental study of azeotropic blend(30\% propane, 55\% n-butane, $15 \%$ iso-butane) refrigerant flow through the serpentine capillary tube in vapour compression refrigeration system", International Journal of Mechanical and Production Engineering Research and Development, 2013.

[9]. Thamir K. Salim, "The effect of the capillary tube coil number on the refrigeration system performance", Tikrit Journal of Engineering Sciences, 2012.

[10]. Akash Deep Singh, "Flow characteristics of refrigerant inside diabatic capillary tube," Thapar University, Patiala, (2009), pp. 1-96.

[11]. M.A. Akintunde, Ph.D. "Effect of Coiled Capillary Tube Pitch on Vapor Compression Refrigeration System Performance," The Pacific Journal of Science and Technology Volume 9. Number 2. November (2008), pp. 284-294. 